
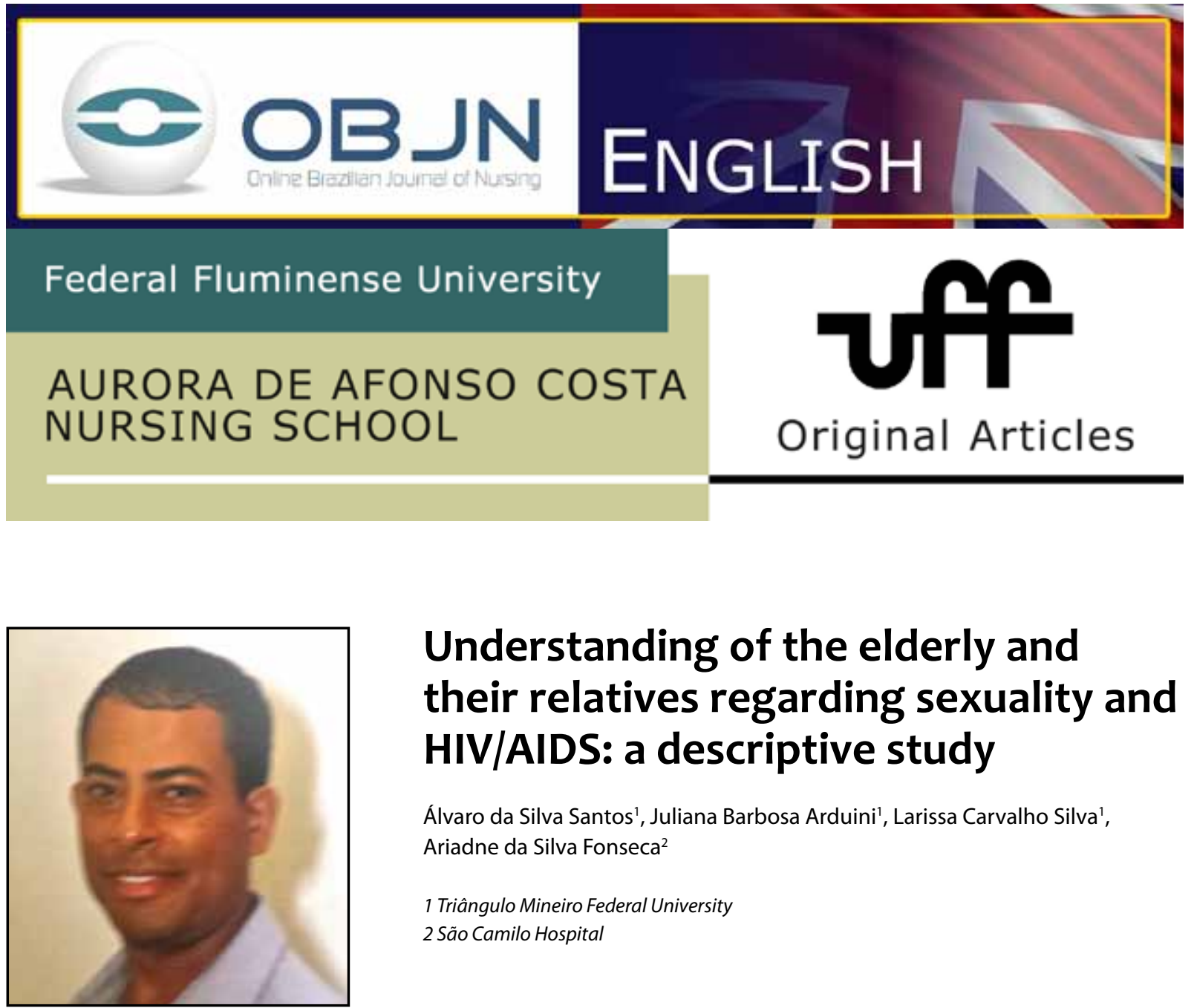

\title{
Understanding of the elderly and their relatives regarding sexuality and HIV/AIDS: a descriptive study
}

\author{
Álvaro da Silva Santos ${ }^{1}$, Juliana Barbosa Arduini' ${ }^{1}$ Larissa Carvalho Silva', \\ Ariadne da Silva Fonseca² \\ 1 Triângulo Mineiro Federal University \\ 2 São Camilo Hospital
}

\section{ABSTRACT}

Aim: To observe the understanding of the elderly and their relatives regarding sexuality and Acquired Immunodeficiency Syndrome (AIDS). Method: This is a descriptive study, using a focus group, interviews and content analysis. Thirty-three seniors citizens were the focus of the research, divided into six groups, together with nine relatives who were also interviewed; all were patients of a Primary Health Care unit located in the city of Uberaba, Brazil. Results: Thirteen categories emerged, which were divided into five groups: male senior citizens, female senior citizens, a mixed group of men and women, and relatives. Discussion: From the main categories identified in the research, it was observed that there is a reduced awareness about AIDS and the association of the disease to death; lack of information and protection during sexual intercourse. Relatives valorize the sexuality of older people and are not aware of public, nation-wide educational campaigns aimed at this age group. Conclusion: There is a lack of understanding about AIDS and its association with death among the elderly, and their sexuality, from the point-of-view of the relatives.

Descriptors: Sexuality; Acquired Immunodeficiency Syndrome; Aged; Community Health Nursing. 


\section{INTRODUCTION}

Brazil has an ageing population with fewer young people, and the number of senior citizens continues to grow at a fast pace. Today, there are more than 20 million senior citizens, and statistics show that from 1998 to 2010 the proportion of senior citizens increased from $8.8 \%$ to $11.1 \%{ }^{(1)}$.

Family must be included in the care provided for their ageing relatives, not only focusing on diseases, but also on sexual health, such as: exchanging information and giving support against diseases that may interfere in sexuality, among others.

In general, society does not provide support for the elderly in terms of their physical and mental demands. However, this same society does not recognize that senior citizens continue to indulge in sexual activity. There are some individuals who work out to keep sexually active; however the majority struggles to maintain a healthy sex life. Some senior citizens report difficulties in talking about sexuality, and move away from the topic as it makes them feel embarrassed, which is a demonstration of a socially constructed prejudice ${ }^{(2)}$.

Sexuality is a central aspect of human beings, which includes identities, social roles, sexual orientation, eroticism, pleasure, intimacy and reproduction. The interaction of biological, psychological, social, economic, political, cultural, ethical, legal, historical, religious and spiritual factors influence sexual practices in every social group $^{(3)}$.

The cases of Acquired Immunodeficiency Syndrome (AIDS) have increased in male and female senior citizens. In the over 50 s (including people over 60 ), the incidence rate of AIDS among women in 2010 increased by $75.9 \%$ when compared to the same group in 1998 (from 5.8 cases for every 100,000 inhabitants to 10.2 cases). The incidence rate among men in the same age group and during the same period increased from 14.5 cases for every 100,000 inhabitants to 18.8 cases. Considering the total number of people in this age group, the increase was $43.4 \%$, rising from 9.9 cases for every 100,000 inhabitants in 1998 to 14.2 cases in $2010^{(4)}$.

As a consequence of the increase in longevity and the ease with which people can engage in sexual relations today, unsafe sexual practices make the elderly more vulnerable to the Human Immunodeficiency Virus (HIV). However, this also generates important implications for collective health, nursing and for other health professions, leading to a search for a strategic approach with regards to information and the protection of the population included in this age group ${ }^{(5)}$.

The diagnosis of the HIV infection in the elderly is more complex, because sometimes diseases associated with the virus, such as pneumonia and dementia, among many others, are common in this stage of life. Sometimes, health professionals spend months of investigation, associating the symptoms with other illnesses, such as Alzheimer's disease and neoplasms, until they finally suspect it is an AIDS case ${ }^{(6)}$.

Educational campaigns and other educational initiatives can be the alternatives to control the spread of AIDS among the elderly. Activities related to health education have been relevant strategies in bringing professionals and the community together, permitting the exchange of knowledge and the clarification of any doubts ${ }^{(7)}$

Considering that a person's way of thinking can determine their practices, the perceptions of the elderly tend to guide their behavior regarding their sexuality; on the other hand, the views of relatives can also influence a senior citizen's sexuality. Therefore, this study aims to understand the perceptions of the elderly and their relatives regarding sexuality and AIDS. 


\section{METHOD}

This is a descriptive study, with a qualitative approach, performed based on the Consolidated Criteria for Reporting Qualitative Research (COREQ): a 32-item checklist for interviews and focus groups ${ }^{(8)}$.

The criteria of inclusion considered for the elderly were: to be 60 years old or over, from both sexes, residing in the area close to the central Primary Health Care Unit (UAPS, in Portuguese), and to accept to participate in this research, as well as signing the Free and Clear Consent Agreement (TCLE, in Portuguese). Thirty-three people were included in this research, all 60 years old or over, who all met the other requirements, such as living in the neighboring area of the central UPAS located in the city of Uberaba, Brazil. Adult relatives, from 18 to 59 years old were also included, from both sexes, who agreed to participate in the study. However, this part of the research was concluded when the answers began to be repeated. As a criterion of exclusion, the presence of a serious cognitive illness was considered for both the senior citizens and their relatives.

As a data collection technique, a focus group was used for the elderly, and an interview was used for their relatives.

Two researchers performed the data collection. One was the moderator of the group, and the other was the observer, who also performed a daily field journal after the focus group. Both also adhered to previous research regarding the collection of information, carried out by two leading researchers.

The researchers used a script with guiding questions, and the testimonies were fully transcribed. The questions that guided the senior citizens' focus groups were:"What is the meaning of sexuality before and after you turn 60 years old?"; "In your point-of-view, how do the people in your family see sexuality in the elderly?";
"What is your understanding of sexually transmitted diseases (STD), AIDS and the means of prevention?" The interviews with the relatives had two main questions: "What is sexuality for you today, and do you see it after the age of 60 years old?"; "What do you know about STDs, AIDS and the means to prevent these illnesses among the elderly?"

There were six focus groups (one single meeting per group), two with elderly women, two with elderly men and two with mixed genders; there were approximately six people per group. Focus groups took place in the meeting room of the health unit, which permitted a tranquil and private place for the participants. For the relatives, the interviews took place in their homes, which were previously scheduled to all take place at the health unit.

The focus group sessions lasted approximately 35 minutes. Fictitious names were used to maintain the anonymity of the subjects of the study. The content of the activities was recorded using an audio device and later fully transcribed. During the transcription, the researchers had a letter for each group $(A, B, C, D, E, F$ - the elderly and $G$ - relatives), and a sequential number in the group.

To analyze the data, thematic content analysis was used, especially when dealing with the communications, as it enables the messages to be understood beyond their initial meanings. It aims to find the essence of the phenomena and the situations in greater depth, permitting to find the semantics of the messages exchanged $^{(9)}$. The descriptions of testimonies were fully transcribed, without the support from software, and after many readings and checks with the interviewees; the descriptions were organized by similarities, which enabled the organization of the categories afterwards.

This research was approved by the Committee of Ethics in Research, at the Triangulo Mineiro 
Federal University (UFTM, in Portuguese), under protocol\# 1583/2010 and performed during the first semester of 2011. The participation in this study by the elderly and their relatives was subject to a previous orientation about the research itself and the signing of the Free and Clear Consent Agreement. In the orientation given, the justification of this study was relayed, which demanded the understanding of the topic by the elderly and their relatives. It aimed to provide data to give better support in dealing with sexuality and HIV/AIDS from the perspective of health professionals and relatives in the care of elderly family members.

The researchers, despite a natural interest in the topic, were unaware of the routines of the interviewees, meaning that they were not able to make value judgments.

\section{RESULTS}

Thirty-three senior citizens participated in this research, and among them, 18 were males. The group was composed of participants from 60 to 88 years of age, with an average age of 70 years old $(S D \pm 7)$. The nine interviewed relatives ages ranged from 30 to 45 years old, with an average age of 41 years old (SD \pm 3 ), and the most predominant relative relationship was daughter. Daughters represented $55.5 \%$ of the relatives; granddaughters represented $22.2 \%$ and sons $22.2 \%$.

The analysis of the transcriptions demonstrated five category groups: $1^{\text {st }}$ - common to all groups of senior citizens (elderly women, elderly men and mixed genders); $2^{\text {nd }}-$ elderly men ( $B$ and $C) ; 3^{\text {rd }}$ - elderly women ( $D$ and $F$ ); $4^{\text {th }}$ - mixed genders ( $A$ and $E$ ); and $5^{\text {th }}$ - relatives of the elderly $(G)$.

Four common categories arose from the groups of elderly people: Unawareness about
AIDS and its association to death; Prevention is only aimed at single or unfaithful men; Use of condoms reduces sexual pleasure; Sexual activity and its challenges. For elderly men, there were two categories: Women do not have the same desire; and health issues and drugs that reduce sexual potency. In the case of elderly women, two categories emerged: Matrimonial frustration; and (Inter) generational communication. For the mixed group, there were two categories: Sexuality can improve during old age; and the existence of an outdated concept of what constitutes a risk group. For the relatives, the analysis demonstrated three categories: Sexuality as an important element for the elderly; Necessity of companionship during old age; and Campaigns against STDs do not target the elderly and are seasonal. Below are the aforementioned categories as discussed by the groups.

\section{- Common categories for the elderly groups}

This group of characteristics demonstrates what common themes were observed among the different groups of elderly people, thus it shows what came up in all groups, either in the men's, women's or mixed gender elderly groups.

Unawareness about AIDS and its association to death

In this category, it was observed that the elderly associate AIDS to death, but they have limited information regarding the illness.

No, I don't know anything about AIDS. (B1)

From what I know, the people infected... usually die. (B5) 
I think that AIDS is a very dangerous

disease... it really kills. (D3)

AIDS... I don't know anything, I only know it kills. (E2)

Prevention is only aimed at single and unfaithful men

In this category, there is a predominance of the idea that prevention is destined only for those that have sexual intercourse with other partners who are not their wives, and that sex at home is free of risks.

Now that you are single and you go out with other women... to have sex... it's more dangerous... (B1)

Single men must use protection... which is not my case... (F4)

You have to wear... the condom... especially for those who go out... (C3)

Well, these people that come and go need to be more careful. Now I don't need any of this, because I stay at home... I'm safer [than them]. (A3)

Use of condoms reduces sexual pleasure

It was a consensus among elderly men and women that the use of male condoms reduces sexual satisfaction, and some also declared they neither know nor used condoms before.

I never used it... but people say it's the same as chewing gum without removing the paper. (C2)
I never used it... it seems it's not the same thing. (E5)

I never used it; who likes to chew gum without removing the paper? (F3)

Sexual activity and its challenges

When questioned about what sexuality represents for them at their actual stage in life, they associated the sexual act and its challenges, however the amplitude of sexuality was not mentioned.

[...] When age comes to you, you start to fail. Now, today, I'm done... I don't think about anything else anymore (C1)

At our age, it's not the same thing anymore... (A3)

[...] We are not able to react the same way as before... (C5)

The difference is considerable... we don't make love anymore. (D2)

\section{- Categories of the group of elderly men}

Women do not have the same desire

In male testimonies, it was observed that there is a load of guilt on women for not performing sexually.

[...] Sometimes... he wants it, but his wife does not want it, and then he feels like looking for another woman. (C2)

When I want it, but she doesn't, I keep myself quiet because only men want it... (C3) 
[...] There are times that I want it and she doesn't... it's hard. (B2)

I think that in the sexual area, we also need to have discipline... if the wife is sick or something like that... (C4)

Health issues and drugs that reduce sexual potency

The deponents of this research related the health issues and the use of medication with sexual potency.

We get older and the illnesses come... the medicine... and l've been through eight surgeries in my body... things go under zero. (B5)

It doesn't happen before you turn $60 .$. the potency fades out... and especially with those... those drugs that we have to have... (B1)

So these drugs they have some counter-effects. (C5)

\section{- Categories of the group of elderly women}

\section{Matrimonial frustration}

When asked about their sexuality, the group made up of women focused only on matrimonial frustrations, demonstrating their deceptions and suggesting an idea that is far from the experienced reality.

Because we imagine how the marital routine is ... and then you live another.
I was really disappointed... that I didn't want to know... about... other men in my life... (F4)

[...] my marriage was a disappointment... there was nothing good about it... my husband lived with another woman for 33 years, he had money... and he didn't give me anything... (F1)

\section{(Inter) generational communication}

It was observed among the testimonies that both daughters and granddaughters supported the continuity of sexual activity, and they also understood that it was part of their relative's life. On the other hand, the sons did not accept this idea, or did not make comments about "this topic".

Today, I talk with my granddaughter... I tell my granddaughter... we discuss things and I talk about sex... and she talks with me about it... you know? (D1)

Well... my daughter tells me it's normal because we have lots of conversations about these things... (D2)

Well, I talk about it with my daughters and I even ask them to buy me the lubricating gel... because we get dry... (D4)

Oh... they don't get it... (F4)

My son... no way... (F3)

[...] I don't talk with my sons about it... (D1) 
- Categories of the group of elderly men and women

Sexuality can improve during old age

This category permits to observe that, for some senior citizens, sexuality is seen as pleasing, healthy and that during their stage of life it does not necessarily tend to worsen.

Sex is a sign of health! (E2)

[...] in my case, for me, it improved...

Today, after we get older it improves.

During the early years, we lacked experience... (A2)

Outdated concept of what constitutes a risk group

In this category, elderly men and women associated the risk of transmission only with people who are homosexually oriented.

[...] Homosexual... here... the first time we heard of it... was a famous fashion designer... internationally known... died about 30 years ago or more... with AIDS, and he was... homosexual. (E4)

Because gays go out more often with men, than straights with women... and they keep on transmitting the disease. (A2)

[...] There was this young man who was homosexual... a close friend... We used to sew and he used to sew with us... then this disease came up. (E3)

\section{- Categories of the group of relatives}

Sexuality as an important element for the elderly

In the testimonies of some relatives, the importance given to the continuity of a sexual life among the elderly was observed.

[...] It is not because the person is elderly that he or she will not do it anymore... sexuality... I think it is important even for the person's self-esteem... (G7)

A more active sexual life... it's good for the mind and the body of the elderly person... (G2)

Necessity of companionship during old age

In this category, relatives of the elderly reported that achieving this stage of life makes these individuals needier and dependent on companionship during their daily routines.

$$
\begin{aligned}
& \text { Because they... during old age are } \\
& \text { needier than ever... They want to find } \\
& \text { a companion... (G6) } \\
& \text { I think it is interesting because the } \\
& \text { person is alone... the children... each } \\
& \text { one of them has obligations, and } \\
& \text { then... I think that this partnership is } \\
& \text { good... (G4) }
\end{aligned}
$$

Campaigns against STDs do not target the elderly and are seasonal

The opinion that prevailed among relatives of the elderly was that the educational campaigns to protect against STDs, and in particular, 
to protect against AIDS, are not aimed at the elderly.

It does not reach a goal among them... I think that they think that old people don't need sex, they don't need to be safe, they don't need to think about it... (G6)

[...] The publicity aimed at the elderly is not... as I usually say... runs three times a year: during carnival, on the... Global HIV Day. And also during gay parades... (G6)

\section{DISCUSSION}

The elderly subjects of this study demonstrated a perception of the difference in the matter of gender and sexuality, valorizing the latter as sexual intercourse. Men mention that women are the ones to blame for sexual inactivity, as well as medications that interfere in their performance. Women, on the other hand, highlight the frustration of marital life and the possibility of information exchange about sexuality with daughters and granddaughters.

One study demonstrated that women do not feel necessarily unsatisfied with the lack of sexual intercourse, and they demonstrate their view of sexuality in a wider perspective; men see sexuality centered on the sexual act and the satisfaction while it is being practiced ${ }^{(10)}$, as demonstrated in this study.

When interviewed together, elderly men and women reported that there is room for improvement regarding the issue of sexuality in the elderly, and reported an old-fashioned concept of what the STD risk groups are. On the common categories of the groups of elderly people, it was observed that there is little understanding regarding AIDS and its association to death, and that the necessity of prevention is only for men with many partners; the lack of necessity of condoms due to sexual dissatisfaction, besides the difficulties to perform sexually during old age, which in this case is again centered only on the sexual act.

Contrary to the answers found in this research, another study showed that elderly men and women valorize their freedom, without the obligation to reproduction and can see the amplitude of sexuality to beyond the sexual act ${ }^{(11)}$.

The relatives demonstrated a perception that sexuality is important for elderly people, the necessity of companionship and the lack of campaigns against STDs and AIDS aimed at the elderly. In a study that compares the understanding of AIDS among the elderly and the young, it demonstrates that it is important to recognize the values and the culture of each individual, and therefore, it is important to promote campaigns aimed at both the young and the old in society, in order to achieve more effective results in prevention, safer sexual activity, promote health to the population in a more equitable way, based on the fact that the number of senior citizens and their understanding about the illness, its contagious cycle and the prevention campaigns are lagging behind when compared to those aimed at young people ${ }^{(12)}$.

It was observed that, despite studies directed to AIDS and many other initiatives to disseminate the findings, the understanding of the elderly regarding the aspects involved in the infection, prevention and treatment of the disease is still limited. A study that took place with a group of senior citizens in the Brazilian state of Goiás corroborates the findings of this study. Some members associate the transmission of HIV/AIDS to sharing utensils, toilet seats and other objects, which demonstrates a lack of understanding in the modes of transmission, as 
well as having prejudice and other discriminatory opinions regarding the infected subjects ${ }^{(13)}$.

For the researchers, the interviewees shared the idea that the preventive methods against STDs are necessary for the young, single adults and those who are unfaithful in their relationships. A 60-year-old man is less receptive to wearing a condom, because he tends to repeat the behavior he used to have during his youth, when he did not wear one. The most feared STDs were gonorrhea and syphilis, treated with antibiotics. When considering the lack of the use of condoms, despite their use being uncommon in this age group, and also despite the fact that women do not feel the need to demand it, men are afraid to lose their erection ${ }^{(6)}$.

The libido, according to the participants, was reduced, and the way they demonstrate their sexuality became impaired. Today's society appreciates the body, especially the female one, when dealing with sexuality. In this culture, the hormonal unbalance and the end of the reproductive cycle are considered the keys to female ageing and the decline of their sexuality ${ }^{(14)}$.

Among the men in the research, penetration is important, as maybe the only or the most considerable role in their sexuality. When compared to the senior citizens in another study, it is shown that there are different meanings, in which there is a perception of feelings, and sexuality was mentioned not only as the sexual act itself ${ }^{(15)}$.

The appreciation of sexuality beyond sexual intercourse must be the topic inserted into the actions in health education among the elderly, in order to make them evaluate the amplitude sexuality has. To have the educational practices working properly, it is necessary that health professionals assume their role as mediators and facilitators, believing in the creation of individual and collective transformations ${ }^{(16)}$. To understand sexuality in the case of men is to perform it better, considering that the elderly are not asexual beings. Depending on the context, individual orientations should take place, and in other moments, these moments should happen in collective spaces.

Based on the testimonies of women in this study, and comparing them to another text, it is perceived that, in the past, women could not talk about sex, and only men had sexual orientation, the latter being free to exercise these lessons with sex professionals ${ }^{(18)}$. For women, any sexual manifestation was not permitted and men did not have to worry about the fulfillment of female sexual desires $^{(17)}$.

Among the categories of the mixed groups, it is possible to infer that the comments were destined to the idea that sexuality does not end in old age, and it can even improve with time. There is also a predominant idea among elderly men and women in this research that homosexuals are more susceptible to AIDS. It is known that with the arrival of AIDS and the dissemination of information through mass media, a global consensus was driven to believe that the most affected population were homosexuals, sex professionals and injectable illegal drug users. These individuals became known as the disseminators of the disease, and deviants of the social norms linked to pleasure, to the use of sex and drugs. It was the disease of the others, of promiscuous people ${ }^{(18)}$.

\section{CONCLUSION}

The results in this study demonstrate the views that the elderly and their relatives have about sexuality and STD/AIDS, and show a common opinion in all the groups, such as: the perception that sexuality does not age, but at the same time it can become harder in old age, depending on the opportunities and experiences lived throughout life. 
AIDS is little known and is not completely associated to death, which shows that the subjects of the research are unaware of available means of treatment and that it is possible to prolong life and guarantee that it has enough quality. The use of condoms for many of them never occurred, because they still have an outdated concept about risk groups, thus believing they are "immune" to STDs, hence, distancing themselves from prevention.

Regarding the relatives of the elderly people interviewed, there is a common understanding that sexuality is a necessity, but, in the possibility of company, and that campaigns against STD/AIDS are not aimed at this age group.

Based on the fact that this is a qualitative study, the lack of the ability to make generalizations limits the reach of these results. On the other hand, it is possible that such results point out the contemporaneity for the majority of Brazilian senior citizens.

The results demonstrated here were presented to the health unit taking part in the research, and they demand interventions in health education on the topic of sexuality and AIDS in elderly care, especially by nurses located in primary health care.

\section{REFERENCES}

1. Instituto Brasileiro de Geografia e Estatística. Censo 2010 [Internet] [cited 2010 Jul 12]. Available from: http://www.censo2010.ibge.gov.br/.

2. Laroque MF, Affeldt AB, Cardoso DH, Souza GL, Santana MG, Lange C. Sexualidade do idoso: comportamento para a prevenção de DST/AIDS. Rev Gaúcha Enferm. 2011; 32 (4):774-80.

3. Freitas KR, Dias SM. Teenagers' perceptions regarding their sexuality. Texto \& Contexto Enferm. 2010; 19(2):351-7.

4. Ministério da Saúde (Brasil). Programa Nacional de DST e AIDS. Bol Epidemiol AIDS. Brasília: Ministério da Saúde; 2011.
5. Andrade HAS, Silva SK, Santos MIPO. AIDS em idosos: vivencias dos doentes. Esc Anna Nery Rev Enferm. 2010; 14(4):712-9.

6. Vieira DL, Sobral B. O corpo envelhece, a sexualidade não: AIDS no diagnóstico diferencial entre as doenças comuns nos idosos. Int Clin Med [Internet] 2009[Cited 2013 Jan 01];2(B6). Available from: http://www.medcenter.com/medscape/ content.aspx?id $=18356$ \&langType $=1046$

7. Joventino ES, Freitas IV, Lima TM, Vieira NFC, Damasceno AKC , Ximenes LB. Educação em saúde na prevenção de enteroparasitoses: estudo descritivo. Online braz j nurs [internet]. 2011 Apr-Ago; 12 (2):565-73. Available from: http://www. objnursing.uff.br/index.php/nursing/article/ view $/ 3253$

8. Tong A, Sainsbury P, Craig J. Consolidated criteria for reporting qualitative research (COREQ): a 32item checklist for interviews and focus groups. International Journal for Quality in Health Care [Internet] 2007 [Cited 2014 Apr 17]; 19(6):349-57. doi:10.1093/intqhc/mzm042

9. Bardin L. Análise de conteúdo. Lisboa: Edições 70; 2011.

10. Rodrigues $\mathrm{CL}$, Duarte $\mathrm{YAO}$, Lebrão $\mathrm{ML}$. Gênero, sexualidade e envelhecimento. Saúde Coletiva, 2009; 6(6):109-12.

11. Torres C, Silva P, Novais C, Carvalho J. Gênero, sexualidade e atividade física: uma leitura sobre masculinidades e feminilidades reconstruídas a luz do envelhecer. RBCEH, 2012; 9(1):9-21.

12. Melo HMA, Leal MCC, Marques APO, Marino JG. O conhecimento sobre AIDS de homens idosos e adultos jovens: um estudo sobre a percepção desta doença. Ciência \& Saúde Coletiva 2012; 17(1):43-53.

13. Pereira GS, Borges Cl. Knowledge about HIV/AIDS in a group of elderly in Anápolis-Goiás. Esc Anna Nery Rev Enferm. 2010; 14(4):720-5.

14. Fernandes MG. Stating elderly women's body and sexuality: the view of gender and generation. Rev Enferm UERJ. 2009; 17(3):418-22.

15. Moraes KM, Vasconcelos DP, Silva ASR, Silva RCC, Santiago LMM, Freitas CASL. The beauty of companionship and sexuality for couples in the best age: caring for elderly couple. Rev Bras Geriatr Gerontol. 2011; 14(4):787-98. 
16. Araújo VS, Guerra CS, Moraes MN, Silva JB, Monteiro CQA, Dias MD. Discourse of the Collective Subject regarding Education of Health in the Aging Process: a descriptive study. Online braz j nurs [Internet]. 2013 Sept; 12 (2):565-73. Available from: http://www.objnursing.uff.br/index.php/ nursing/article/view/4093

17. Fernandes MG, Garcia LG. The aged body: perception and experience of elderly women. Interface - comunic, saúde, educ. 2010; 14(35):879-90.

18. Saldanha AA, Felix SM, Araujo LF. Representations about Aids in old age by coordinators of groups the third age. Psico-USF. 2008; 13(1):95-103.

Contribution of the Authors: Álvaro da Silva Santos coordinated the research project, proceed to the critical reading, closing the categories and reviews of the final manuscript. Juliana Barbosa Arduíni and Larissa Carvalho Silva collected the data, transcription and precategorization of data. Ariadne da Silva Fonseca performed the categorization of data and final critical analysis of the manuscript.
All authors participated in the phases of this publication in one or more of the following steps, in According to the recommendations of the International Committee of Medical Journal Editors (ICMJE, 2013): (a) substantial involvement in the planning or preparation of the manuscript or in the collection, analysis or interpretation of data; (b) preparation of the manuscript or conducting critical revision of intellectual content; (c) approval of the versión submitted of this manuscript. All authors declare for the appropriate purposes that the responsibilities related to all aspects of the manuscript submitted to OBJN are yours. They ensure that issues related to the accuracy or integrity of any part of the article were properly investigated and resolved. Therefore, they exempt the OBJN of any participation whatsoever in any imbroglios concerning the content under consideration. All authors declare that they have no conflict of interest of financial or personal nature concerning this manuscript which may influence the writing and/or interpretation of the findings. This statement has been digitally signed by all authors as recommended by the ICMJE, whose model is available in http://www. objnursing.uff.br/normas/DUDE_eng_13-06-2013.pdf

Received: 03/25/2013

Revised: 05/03/2014

Approved: 05/19/2014 